\title{
Effects of Cognitive Restructuring Techniques on Physical Activity in Older Adults
}

\author{
Keri D. Larsen*, Sabita Shrestha, Katie Jones
}

Department of Kinesiology and Health Studies, Southeastern Louisiana University, SLU Box 10845, Hammond, LA 70402, USA

\begin{abstract}
Article Details
Article Type: Research Article

Received date: $23^{\text {rd }}$ March, 2019

Accepted date: $12^{\text {th }}$ July, 2019

Published date: $15^{\text {th }}$ July, 2019

"Corresponding Author: Keri D. Larsen, Department of Kinesiology and Health Studies, Southeastern Louisiana University, SLU Box 10845, Hammond, LA 70402, USA. E-mail. keri.larsen@selu.edu

Citation: Larsen KD, Shrestha S, Jones K (2019) Effects of Cognitive Restructuring Techniques on Physical Activity in Older Adults. J Pub Health Issue Pract 3: 141. https://doi.org/10.33790/jphip1100141.

Copyright: $\left({ }_{2} 2019\right.$, This is an open-access article distributed under the terms of the Creative Commons Attribution License 4.0, which permits unrestricted use, distribution, and reproduction in any medium, provided the original author and source are credited.
\end{abstract}

\begin{abstract}
Background: This study examined the effects of cognitive restructuring techniques on self-efficacy and physical activity.

Methods: An intervention was designed to increase the self-efficacy of 61 older adults and then evaluated to measure the effectiveness of the intervention. A pretest/posttest analysis of variance was conducted to look for differences in knowledge, attitudes, physical activity, and self-efficacy.

Results: Significance was found on the knowledge assessment, $F(1$, $59)=18.570, \mathrm{p}<.01$; attitude assessment, $\mathrm{F}(1,54)=6.317, \mathrm{p}<.05$; physical activity assessment, $\mathrm{F}(1,54)=5.054, \mathrm{p}<.05$; confidence portion of self-efficacy, $\mathrm{F}(1,44)=6.477, \mathrm{p}<.05$; control portion of self-efficacy, $\mathrm{F}(1,57)=4.475, \mathrm{p}<.05$; and the PPA portion of selfefficacy, $\mathrm{F}(1,58)=4.580, \mathrm{p}<.05$.

Conclusions: Results showed not only a change in self-efficacy, but in actual behavior change or an increase in physical activity. This behavior was maintained at one-month follow-up. Results indicate that an intervention on this level is sufficient to produce a change in knowledge, attitudes and behavior.
\end{abstract}

Keywords: Cognitive Restructuring, Self-efficacy, Older Adults, Exercise

\section{Introduction}

In recent years, attention has focused on regular physical activity as a means of enhancing the quality of life and functional capacity of older adults. Exercise, even when started late in life, has been shown to reduce the effects of aging on the body, improve functioning in the cardiovascular system, pulmonary systems, musculoskeletal systems and enhance mood [1].

The benefits of exercise have been demonstrated repeatedly for promoting successful aging and have been shown to be advantageous to individuals, regardless of their particular stage in life [2,3]. More specifically, exercise has shown to have positive effects on the health of individuals from childhood years through the 80 's and beyond $[2,3]$. In fact, research indicates that there is no defined age at which individuals stop receiving health benefits from exercise or physical activity [4].

Conversely, a lack of exercise or physical inactivity is associated with many of the characteristics that are attributed to growing older such as: heart disease, adult-onset diabetes, reduced functional capacity, reduced mobility and many others $[5,6]$. Some of the decline in physical robustness in older adults is considered inevitable [5]. However, research has shown that much of the decline generally thought to be due to age is actually due to a lack of physical exercise $[7,8]$. For instance, diminished muscle strength and stiffening of the joints can be attributed to a sedentary lifestyle. Moreover, almost all body systems deteriorate when inactive [1].

Physical activity decreases with age; however, declines in activity are not the result of aging. The National Center for Health Statistics reported in 2004 that $50 \%$ of adults 65 years of age and older engage in no physical activity, $65 \%$ of adults aged 20 to 74 are overweight and $31 \%$ are considered obese [1]. The 2016 survey by National Health Interview Survey showed that the percent of adults 65 to 74 years of age who do not engage in physical activity is $50 \%$. However, $65 \%$ adults aged 75 and over do not meet physical activity guidelines while only $8.4 \%$ of adults the same age meet the full guidelines for both aerobic and muscle-strengthening activity. Also, of adults aged 20 and over, $37.9 \%$ are considered obese [9]. According to federal guidelines for physical activity, Healthy People 2020 recommends and "increase in the proportion of the adults who engage in aerobic physical activity of at least moderate intensity for at least 150 minutes/ week, or 75 minutes/week of vigorous intensity, or an equivalent combination" and "increase the proportion of adults who perform muscle-strengthening activities on 2 or more days of the week" [2].

In the distant past, a new way to regard the recommended level of physical activity and/or exercise necessary for older adults has surfaced and more recently recommendations have turned into guidelines [10]. There is accumulating evidence that some physical activity, even in small increments of time, is better than no physical activity; and, of course, more physical activity is better than less [10].

According to the US Surgeon General's Report on Physical Activity and Health (1996) and the National Center for Health Statistics (2004) older adults can obtain significant health benefits with a moderate amount (about 30 minutes) of physical activity, preferably daily $[1,11]$. According to the US Surgeon General [2], regular physical activity that is performed on most days of the week, reduces the risk of developing some illness and even reduces the rate of death from some types of cancer [2].

Studies have shown that moderate exercise or physical activity, 
at least half an hour for three times a week is an important aid in controlling weight, keeping bones strong, building muscle strength, conditioning the heart and lungs and relieving stress [12,13].

The key question here is why do older adults not participate in regular physical activity and/or exercise? There are numerous barriers to participation in physical activity and exercise for older adults, including neighborhood safety concerns and access to facilities [14]. Research has tried to explain how perceived barriers such as a lack of knowledge or uncertainty about the benefits of exercise or fear of being incapable can interfere with exercise participation [15]. Dealing with psychological barriers appears to be an important area for interventions directed toward increasing physical activity and exercise in older adults.

According to O'Neill et al. [16] perceived barriers are the potential negative aspects of a particular health action that may act as a deterrent for undertaking a recommended health promotion behavior [16]. They postulate that there are four specific types of perceived barriers to exercise and/or physical activity for older adults: psychological, administrative, physical/health and knowledge [16]. O'Brien Cousins [8] expands the psychological categories to specify four barriers: beliefs about coming to physical harm, beliefs about experiencing negative social outcomes, beliefs regarding negative psychological consequences and other beliefs related to the environment or nature of the activity [8].

Bandura $[17,18]$ stipulates that the psychological barriers to exercise and/or physical activity are the most important type of perceived barriers to examine when trying to understand why older adults do not participate in exercise and/or physical activity. O'Brien Cousins [8] concurs with this finding $[8,17,18]$. She found that the main barriers to participation in late-life exercise and/or physical activity are psychological in nature and centered on negative attitudes, feeling foolish, and feeling inferior to other participants [8]. Costello et al. [19] found that the inactive focus group reported six major barriers to physical exercise: lack of time (including difficulties prioritizing), self-discipline, motivation, potential for injury, boredom, and intimidation. The thought of joining exercise groups that were established was intimidating because of the concern that other participants would have "to wait for me" or they would "slow the class down" causing additional barriers to exercising. Most of the barriers mentioned seem to be psychological in nature.

Psychological barriers might be formidable obstacles to undertaking activities documented to promote health. O'Brien Cousins et al. [20] found that there is "a conscious resistance to fitness activity in later life even though most older adults agree that physical exercise is 'good for you'". Many older adults believe that they should not participate in any type of physical activity because they are too old and may be injured [16,21]. Others believe that regular exercise would serve no purpose for them because their body is beyond repair [22]. Additionally, both physically active and physically inactive older adults believe that the potential for injury is both a barrier to participating in regular physical activity and a disadvantage of exercising for older adults [19]. Some older adults are not aware of the benefits of exercise and/or physical activity and some do not think that they are able to perform the exercises to receive the benefits [23]. These attitudes regarding their involvement in exercise (selfefficacy) construct barriers to their participation and undermine their sense of self-efficacy [24].

It is important to consider whether or not older adults refrain from participating in any type of exercise or physical activity because they believe they are too old, or they are afraid of possible injuries, or they do not believe they can perform any type of physical activity because it helps illustrate the importance of psychological barriers in explaining why older adults are sedentary. Furthermore, sufficient evidence suggests that self-efficacy in regard to physical activity is key to why many older adults are not even attempting to participate [23-25].

Bandura [17] presented a theory of social development that has been used as a method of influencing individuals to make behavior changes such as the implementation of exercise or physical activity into one's lifestyle [17]. Social Cognitive Theory provides specific concepts that influence motivation to adopt a behavior such as physical activity [26]. One of the key components of Bandura's theory is self-efficacy. According to Bandura [17], self-efficacy represents an individual's confidence in his/her ability to successfully perform a specific behavior [17]. In this study, self-efficacy is used in the context of physical activity and the older person's confidence in his/her ability to successfully perform some aspects of physical activity. An attempt to change an older person's self-efficacy, in terms of regular physical activities by using cognitive restructuring techniques was employed in the intervention component of this study. Cognitive restructuring is a technique of cognitive therapy that enables one to identify negative, irrational beliefs and replace them with fact-based, rational statements.

Research in other areas, such as memory, has employed cognitive restructuring techniques successfully [27]. Some work has addressed the relationship between self-efficacy and physical activity, but these studies have not attempted to modify self-efficacy through direct intervention [24].

The purpose of this study was to use cognitive restructuring as a psycho-educational intervention. A four-week course was administered to produce changes in self-efficacy for physical activity, and to determine whether those changes, if they occurred, led to changes in behavior.

\section{Materials Methods}

Eighty-two participants were recruited from intact educational programs and residential facilities. Notices were mailed out to the participants on the mailing lists of the residential and educational facilities. Also, flyers were posted at the chosen residential and educational facilities. Presentations describing the study were given to potential participants as a recruitment tool. All participants who were willing to participate were assigned to the treatment group.

Participants attended classes for two hours each week for a total of four weeks. During each class period a break was provided between sessions. The testing was embedded in the course presentation. All subjects were pre-tested before any part of the course was delivered in Session One. Post-testing occurred at the end of Session Four. Table 1 lists the measures used and the order of presentation. All subjects completed the instruments in the same sequence and the knowledge assessments were completed before the attitudinal ones in an attempt to control for bias.

The Facts About Exercise and Growing Older quiz was designed by the author for this study. It has 20 true-false questions that are designed to determine a knowledge base regarding exercise and growing older. This format was selected because of ease of administration and because the format mirrors other widely known informational tests of knowledge about aging. Questions were designed to identify the level of knowledge the participants have about the benefits of exercise for older adults and to address the content of the course which drew upon information from booklets published by the National Institute on Aging, the Canadian Association of Exercise Physiologists and other books in the field. Several examples of the questions on this quiz are as follows: 1) In order to receive benefit, levels of physical activity must be high; 2) Older adults cannot benefit as much from strength building programs as younger adults; and 3) Stretching and flexibility exercises can help people recover from injuries as well as prevent injuries from occurring.

The quiz was tested for content validity and appropriate wording 


\begin{tabular}{|c|c|c|c|c|}
\hline & Week 1 & Week 2 & Week 3 & Week 4 \\
\hline Assessments & $\begin{array}{l}\text { Informed Consent Form } \\
\text { Pretest } \\
\text { - } \quad \text { Facts About Exercise and Growing } \\
\text { Older } \\
\text { - } \quad \text { Godin Leisure-Time Exercise } \\
\text { Questionnaire } \\
\text { - } \quad \text { Older Adults Attitudes About } \\
\text { Physical Activity and Exercise } \\
\text { - } \quad \text { Perceived Barriers Questionnaire } \\
\text { - } \quad \text { Physical Self-Efficacy Scale } \\
\text { Health Status Questionnaire } \\
\quad \text { Demographic Data Sheet }\end{array}$ & $\begin{array}{l}\text { Physical } \\
\text { Activity } \\
\text { Log }\end{array}$ & $\begin{array}{l}\text { Physical } \\
\text { Activity } \\
\text { Log }\end{array}$ & $\begin{array}{ll}\text { Post Test } \\
\text { - } & \text { Facts About Exercise and Growing } \\
& \text { Older } \\
\text { - } & \text { Godin Leisure-Time Exercise } \\
& \text { Questionnaire } \\
\text { - } & \text { Older Adults Attitudes About } \\
& \text { Physical Activity and Exercise } \\
\text { - } & \text { Perceived Barriers Questionnaire } \\
\text { - } & \text { Physical Self-Efficacy Scale } \\
\text { - } & \text { Health Status Questionnaire } \\
& \text { Demographic Data Sheet }\end{array}$ \\
\hline $\begin{array}{l}\text { Follow-Up } \\
\text { *A month later }\end{array}$ & & & & Physical Activity Log \\
\hline
\end{tabular}

Table 1. Pretest and Posttest Assessment Schedule

by a group of ten Exercise Physiology of Aging graduate students and an exercise physiologist. Upon reviewing, modifications were made accordingly. The quiz was administered to 90 college students in various labels of courses. The courses were as follows: a class of Exercise Physiology students (Group 1), a class of Health Issues in Aging students (Group 2), a class of Drugs and Society students (Group 3) and a class of Human Sexuality students (Group 4). As expected, those in the two advanced courses (Exercise Physiology and Health Issues in Aging) scored higher than those in the lower level courses. Post hoc analysis using Scheffe's test showed a significant difference between groups 1 and 4 . An F value was reported: F(3, $86)=3.29 ; \mathrm{p}<.05)$. No other significant differences were found.

The Older Adults Attitudes Toward Physical Activity and Exercise is a self-administered assessment to gauge the attitudes of older adults toward physical activity and exercise [28]. This attitudinal scale was developed using a random sample of 471 people over the age of 50. A confirmatory factor analysis was conducted to establish construct validity. Four factors emerged and internal consistency estimates were obtained. Reliabilities for each factor are as follows: Tension Release Attitudes (.89), Health Promotion Attitudes (.81), Vigorous Exercise Attitudes (.76), and Social Benefits Attitudes (.68).

The Godin Leisure-Time Exercise Questionnaire [29] was utilized to assess an individual's usual activity level [29]. This questionnaire attempts to establish how many times per week, on average, the participants engage in different levels of exercise and if the participants engage in activity long enough to work up a sweat. The scale has been widely used with a variety of population ages ranged from 18 to 65 yrs. old, and the reliability is at 0.74 with $\mathrm{p}<.05$.

Existing measures were used to assess aspects of self-efficacy to determine the types of barriers that participants believe might interfere with their exercise participation, outcome expectations, and evaluation. The assessment was developed by Dzewaltowski DA et al. [30] as an open-ended approach to assessing self-efficacy on a group of 254 undergraduate students and since this assessment contained two highly correlated (.79) measures of efficacy, they were combined [30]. Reliability reported at .92 .

The Physical Self-Efficacy Scale [31] is a slightly modified version of the Physical Self-Efficacy Scale developed by Rychman and Cantrell et al. [31,32]. This standardized assessment has a testretest reliability of .85 and a test of internal consistencies yielded a coefficient alpha of .85 .

Participants also completed a series of demographic and health questions: age, sex, marital status, race, employment status, income, educational attainment, and current or previous occupation. For each week, while the intervention was ongoing, participants were asked to complete a physical activity $\log$, detailing all physical activity for the prior week. This Log was created by the author. One month after the intervention was completed, participants received an additional Physical Activity log to report their levels of activity postintervention.

Participants were instructed to complete and return the $\log$ in the provided postage-paid, self-addressed envelope. Motivational techniques such as rewards or incentives were awarded throughout the progression of the course to encourage completion of the Physical Activity Logs.

This psycho-educational course has a two-component design. The first hour of the course concentrated on a traditional lecture/discussion format dealing with aging and physical activity. The second hour was devoted to cognitive restructuring activities to

\begin{tabular}{|l|l|l|l|}
\hline Week 1 & Week 2 & Week 3 & Week 4 \\
\hline Introduction to Physical & Benefits/Risks of Physical & Types of Exercises/Goal & Staying Motivated/ \\
Activity:The Fountain of & Activity; Barriers to Physical & $\begin{array}{l}\text { Setting/Building a Program } \\
\text { Demonstrations \& Techniques }\end{array}$ & \\
Health & Activity & Exaggerated Self- & Self-Criticism; Quiz on \\
\hline Cognitive Restructuring & Awfulizing; Exaggerated & Statements; Mind-Reading & Cognitive Distortions \\
\hline Introduction; Overgeneralizing & Self- Expectations & \\
\hline
\end{tabular}

$$
\text { Table 2. Weekly Course Content }
$$


challenge misinterpretations and to provide the skills to change these interpretations (self-efficacy). Refer to Table 2 for the weekly course breakdown and Table 3 for a detailed list of examples for the cognitive distortions that were focused on in this course

\begin{tabular}{|l|l|l|}
\hline Negative Thought & Distorted Thinking & Rational Thought \\
\hline $\begin{array}{l}\text { All people my age are too old to start a } \\
\text { successful exercise program. }\end{array}$ & Over generalization & $\begin{array}{l}\text { I have learned that you can begin } \\
\text { exercising and benefit from it at my age. }\end{array}$ \\
\hline $\begin{array}{l}\text { Sue goes to her aerobic exercise class, } \\
\text { looks around and says, "I am terrible at } \\
\text { this." }\end{array}$ & Awfulizing & $\begin{array}{l}\text { "I know I will perform better next time, } \\
\text { and I do like the music." }\end{array}$ \\
\hline $\begin{array}{l}\text { "I have been walking at the mall for } \\
\text { almost a week now, I should be able to } \\
\text { keep up with those people." }\end{array}$ & Exaggerated self-expectations & $\begin{array}{l}\text { "People in this group have been walking } \\
\text { for a year. I am already improving and I } \\
\text { sure do feel better." }\end{array}$ \\
\hline $\begin{array}{l}\text { "Everyone else can lift heavier weights } \\
\text { than me. I am the worst in the group." }\end{array}$ & Exaggerated self-statements & $\begin{array}{l}\text { "I am benefiting from lifting these } \\
\text { weights. My technique is good." }\end{array}$ \\
\hline $\begin{array}{l}\text { "Everyone must think I look stupid in this } \\
\text { get-up I'm wearing." }\end{array}$ & Mind reading & $\begin{array}{l}\text { "People are looking at the instructor and } \\
\text { focusing on themselves, not me." }\end{array}$ \\
\hline $\begin{array}{l}\text { "I wasn't able to walk my usual distance } \\
\text { today. I might as well quit this." }\end{array}$ & Self-criticism & $\begin{array}{l}\text { "It is unseasonably warm today. That is } \\
\text { why I am having trouble. Tomorrow a } \\
\text { cool front is predicted." }\end{array}$ \\
\hline
\end{tabular}

Table 3. Cognitive Distortions

\section{Results}

Eighty-two participants were recruited from intact educational programs and residential facilities. The pretest mean for age (ranging from 66 to 86), along with the demographic characteristics are summarized in Table 4.

\begin{tabular}{|c|c|c|}
\hline Means: & & $\mathrm{n}=41$ \\
\hline Age & & 76 \\
\hline \multicolumn{3}{|c|}{ Characteristics of Participants: } \\
\hline & Male/Female & $5 / 36$ \\
\hline \multicolumn{3}{|c|}{ Marital Status } \\
\hline & Single/Never Married & 0 \\
\hline & Widow/Widower & 21 \\
\hline & Married & 14 \\
\hline & Separated/Divorced & 5 \\
\hline & No Response & 1 \\
\hline \multicolumn{3}{|l|}{ Race } \\
\hline & Asian American & 1 \\
\hline & Hispanic & 0 \\
\hline & African American & 4 \\
\hline & White & 1 \\
\hline & Other & 0 \\
\hline & No Response & 2 \\
\hline \multicolumn{3}{|c|}{ Work Status } \\
\hline & Employed (full or part-time) & 4 \\
\hline & Retired & 26 \\
\hline & Unemployed & 1 \\
\hline & Full-time Homemaker & 10 \\
\hline \multicolumn{3}{|l|}{ Income } \\
\hline & Under $\$ 20,000$ & 9 \\
\hline & $\$ 20,000-\$ 39,000$ & 14 \\
\hline & $\$ 40,000-\$ 59,000$ & 1 \\
\hline & $\$ 60,000$ and above & 6 \\
\hline & No Response & 11 \\
\hline
\end{tabular}




\begin{tabular}{|l|l|l|}
\hline Education & & \\
\hline & Some High School & 4 \\
\hline & High School Diploma & 4 \\
\hline & Some College & 16 \\
\hline & College Degree & 13 \\
\hline & Some Graduate Work & 2 \\
\hline & Graduate Degree & 2 \\
\hline & No Response & 0 \\
\hline
\end{tabular}

Table 4. Demographic characteristics of the groups

Twenty-one of those pretested attended two or fewer classes, did not complete the posttest assessments, or their ages did not fall in the required range so their data was not analyzed. Of the remaining 61 participants, all met the requirements of 1) attendance at $75 \%$ or more classes and 2) being available for assessment at posttest. The basic design of this study was a non-equivalent groups pretestposttest design. The repeated measures analysis included only the 61 participants with test scores.

Repeated measures analysis of variance were performed on the knowledge assessment, attitude assessment, self-efficacy assessments, and physical activity assessment on the 61 participants with complete data using a between-subjects factor of group.
An alpha level of .05 was set as the significance level on all quantitative analyses. Twenty of the forty-one treatment group participants completed all Physical Activity Logs (total of $80 \operatorname{logs}$ ). In addition, all logs were thematically analyzed by two independent expert readers in order to develop a thick description of change as perceived by the participants.

Significance was found on the knowledge assessment, $F(1$, $59)=18.570, \mathrm{p}<.01$; attitude assessment, $\mathrm{F}(1,54)=6.317, \mathrm{p}<.05$; physical activity assessment, $\mathrm{F}(1,54)=5.054, \mathrm{p}<.05$; confidence portion of self-efficacy, $\mathrm{F}(1,44)=6.477, \mathrm{p}<.05$; control portion of self-efficacy, $F(1,57)=4.475, \mathrm{p}<.05$; and the PPA portion of selfefficacy, $\mathrm{F}(1,58)=4.580, \mathrm{p}<.05$. Table 5 presents the group means for all assessments.

\begin{tabular}{|l|l|l|}
\hline MEASURE & TREATMENT \\
\hline & Pretest & Posttest \\
\hline Knowledge & 15.317 & 18.415 \\
\hline Attitudes & 57.889 & 59.694 \\
\hline Physical Activity/Godin & 26.222 & 32.569 \\
\hline Self Efficacy: & \multicolumn{2}{|l|}{} \\
\hline Confidence & 44.026 & 59.240 \\
\hline Satisfaction & 3.038 & 2.590 \\
\hline Control & 59.744 & 70.000 \\
\hline PPE & 31.000 & 33.975 \\
\hline
\end{tabular}

Table 5. Means for all quantitative assessments by group

\section{Discussion and Conclusions}

This study had four specific objectives. They were: (1) To develop a multifaceted intervention program that incorporates knowledge about physical activity and aging, attitudes about physical activity, and cognitive restructuring techniques to address irrational beliefs about the person's ability to exercise, (2) To test the effectiveness of this program in changing knowledge, attitudes, and self-efficacy, (3) To determine if the psycho-educational intervention was sufficient to increase physical activity, (4) To determine if the intervention produced behavioral changes in the form of different types of physical activity.

The first objective was accomplished by incorporating knowledge and physical activity and aging, attitudes about physical activity, and cognitive restructuring techniques to address irrational beliefs about the participant's ability to exercise. For the second objective, results indicate that there was a positive change in knowledge about physical activity, attitudes about physical activity, and a change in self-efficacy regarding physical activity. For the third objective, results indicate that the psycho-educational intervention was sufficient to increase physical activity and that higher level of physical activity was maintained at one-month follow-up for the treatment group. For the fourth objective, results indicate that the treatment group responded with many different types of physical activity which implies that they were able to formulate a variety of ways to incorporate physical activity into their everyday lives. This was even further validated by the fact that the types of leisure activity changed on the logs. For instance, many participants started off reporting leisure time activities such as bingo, cards, and watching television. By the end of the intervention and follow-up, most of the participants were reporting leisure time activities such as dancing, yoga, walking and a variety of other activities.

As a whole, this intervention was effective in increasing knowledge 
about physical activity and aging; changing attitudes about physical activity from less positive to more positive; increasing the level of self-efficacy regarding physical activity; and creating a change in the types of leisure activities that the participants performed and in positive behavior change or an increase in physical activity. These results indicate that an intervention on this level is sufficient to produce a change in knowledge, attitudes and ultimately, behavior.

It would be interesting to investigate whether or not this psychoeducational course would change behavior only through increasing knowledge and utilizing cognitive restructuring techniques and whether or not attitudes about physical activity play a role in increased self-efficacy regarding physical activity and increased physical activity levels. Since the likelihood of developing a true random sample is low, a study with stipulated conditions such as selecting a sample between certain ages, economic statuses, educational levels, ethnic backgrounds and physical activity level should be conducted.

\section{References}

1. National Center for Health Statistics (2004, September) Health, United States, with chartbook on trends in the health of Americans. DHHS Publication No. 2004-1232. Hyattsville, MD.

2. U.S. Surgeon General. (2004) Report on physical activity and health.

3. Healthy People 2020 (2010) Physical Activity.

4. Chodzko-Zajko WJ, Proctor DN, Fiatarone S, Mirson CT, Niqq CR et al. (2009), July 41, Am College of Sports Med Position Stand: Exercise \& Physical Activity for Older Adults, Medicine, Science Sports in Exercise.

5. Stewart AL, King AC, Haskell WL (1993) Endurance exercise and health-related quality of life in 50-65 year old adults. The Gerontologist 33: 782-789.

6. Alberta Centre for Well-Being (1996) Physical activity and older Albertans: Results from the National Survey on Aging and Independence. Research Update.

7. Unger JB, Johnson A, Marks G (1997) Functional decline in the elderly: Evidence for direct and stress-buffering protective effects of social interactions and physical activity. Annual Behav Med 19: 152-160.

8. O'Brien Cousins S (1998) Exercise, Aging, and Health: Overcoming Barriers to an Active Old Age. Alberta: Taylor \& Francis.

9. National Health Interview Survey (2016).

10. American College of Sports Medicine (2004) ACSM Position Stand on Exercise for Older Adults.

11. US Surgeon General's Report on Physical Activity and Health (1996).

12. Zaleski AL, Taylor BA, Panza GA, Wu Y, Pescatello LS et al. (2016) Coming of Age: Considerations In the Prescription of Exercise For Older Adults. Methodist DeBakey Cardiovascular J 12: 98-104.

13. Ruuskanen JM, Ruoppila I (1995) Physical activity and psychological well-being among people aged 65 to 84 years. Age and Aging 24: 292-296.

14. Booth ML, Owen N, Bauman A, Clavisi O, Leslie E (2000) Social-cognitive and perceived environment influences associated with physical activity in older Australians. Prevent Med 31: 15-22.

15. O'Brien Cousins S (2000) My heart couldn't take it: Older women's beliefs about exercise benefits and risks. The Journals of Gerontology Series B: Psychol Sciences and Soc Sci 55: P283-P294.
16. O'Neill K, Reid G (1991) Perceived barriers to physical activity by older adults. Canadian J Public Helath 82: 392-396.

17. Bandura, A (1977) Self-efficacy: Toward a unifying theory of behavioral change. Psychol Rev 84: 191-215.

18. Bandura, A (1997) Self-efficacy: The exercise of control. New York: Freeman.

19. Costello E, Kafchinski M, Vrazel J, Sullivan P (2011) Motivators, barriers, and beliefs regarding physical activity in an older adult population. J Geriatr Phys Ther 34: 138-47.

20. O'Brien Cousins S, Janzen W (1998) Older adults' beliefs about exercise. In S. O'Brien Cousins, Exercise, aging and health: Overcoming barriers to an active old age (pp. 71-96). Philadelphia: Taylor \& Francis.

21. Resnick B, Spellbring AM (2000) Understanding what motivates older adults to exercise. J Gerontologl Nurs 26: 34-42.

22. Rhodes RE, Martin AD, Taunton JE, Rhodes EC, Donnelly M et al. (1999) Factors associated with exercise adherence among older adults: An individual perspective. Sports Med 28: 397411.

23. McAuley E, Blissmer B, Katula J, Duncan TE, Mihalko SL (2000) Physical activity, self-esteem, and self-efficacy relationships in older adults: A randomized controlled trial. Annual Behavior Med 22: 131-139.

24. Lachman ME, Jette A, Tennstedt S, Howland J, Harris BA et al. (1997) A cognitive-behavioral model for promoting regular physical activity in older adults. Psychol Health Med 2: 251261.

25. Lachman ME, Firth KM (2004) The adaptive value of feeling in control during midlife. In O. G. Brim, C. D. Ryff, \& R. Kessler (Eds.), How healthy are we?: A national study of well-being at midlife (p. 320-349). Chicago: University of Chicago Press.

26. Bandura A (2001) Social cognitive theory: An agentic perspective. Am Rev Psychol 52: 1-26.

27. Caprio-Prevette MD, Fry PS (1996) Memory enhancement program for community-based older adults: development and evaluation. Exp Aging Res 22: 281-303.

28. Terry PC, Biddle SJ, Chatzisarantis N, Bell RD (1997). Development of a test to assess the attitudes of older adults toward physical activity and exercise. Attitudes Toward Activity 5: 111- 125 .

29. Godin G, Shephard RJ (1985) A simple method to assess exercise behavior in the community. Can J Applied Sport Sci 10: 141-146.

30. Dzewaltowski DA (1994) Physical activity determinants: A social cognitive approach. Med Sci Sports Exe 26: 1395-1399.

31. Courneya KS, McAuley E (1995) Reliability and discriminant validity of subjective norm, social support, and cohesion in an exercise setting. J Sport Exe Psychol 17: 325-337.

32. Ryckman RM, Robbins MA, Thornton B, Cantrell P (1982) Development and validation of a physical self-efficacy scale. J Personality Soc Psychol 42: 891-900. 